\title{
Adaptive neuro-fuzzy inference system for temperature and humidity profile retrieval from microwave radiometer observations
}

\author{
K. Ramesh ${ }^{1}$, A. P. Kesarkar ${ }^{2}$, J. Bhate ${ }^{2}$, M. Venkat Ratnam ${ }^{2}$, and A. Jayaraman ${ }^{2}$ \\ ${ }^{1}$ Department of Computer Applications, Anna University, Regional Center, Tirunelveli, Tamil Nadu 627 005, India \\ ${ }^{2}$ National Atmospheric Research Laboratory, Gadanki 517 112, Chittoor District, Andhra Pradesh, India \\ Correspondence to: A. P. Kesarkar (amit@narl.gov.in, amit.kesarkar@gmail.com)
}

Received: 13 December 2013 - Published in Atmos. Meas. Tech. Discuss.: 20 March 2014

Revised: 27 November 2014 - Accepted: 11 December 2014 - Published: 22 January 2015

\begin{abstract}
The retrieval of accurate profiles of temperature and water vapour is important for the study of atmospheric convection. Recent development in computational techniques motivated us to use adaptive techniques in the retrieval algorithms. In this work, we have used an adaptive neuro-fuzzy inference system (ANFIS) to retrieve profiles of temperature and humidity up to $10 \mathrm{~km}$ over the tropical station Gadanki $\left(13.5^{\circ} \mathrm{N}, 79.2^{\circ} \mathrm{E}\right)$, India. ANFIS is trained by using observations of temperature and humidity measurements by co-located Meisei GPS radiosonde (henceforth referred to as radiosonde) and microwave brightness temperatures observed by radiometrics multichannel microwave radiometer MP3000 (MWR). ANFIS is trained by considering these observations during rainy and non-rainy days (ANFIS(RD + NRD)) and during non-rainy days only (ANFIS(NRD)). The comparison of ANFIS(RD + NRD) and ANFIS(NRD) profiles with independent radiosonde observations and profiles retrieved using multivariate linear regression (MVLR: RD + NRD and NRD) and artificial neural network (ANN) indicated that the errors in the ANFIS(RD + NRD) are less compared to other retrieval methods.

The Pearson product movement correlation coefficient $(r)$ between retrieved and observed profiles is more than $92 \%$ for temperature profiles for all techniques and more than 99\% for the ANFIS(RD + NRD) technique Therefore this new techniques is relatively better for the retrieval of temperature profiles. The comparison of bias, mean absolute error (MAE), RMSE and symmetric mean absolute percentage error (SMAPE) of retrieved temperature and relative humidity (RH) profiles using ANN and ANFIS also indicated that profiles retrieved using ANFIS(RD + NRD) are signif-
\end{abstract}

icantly better compared to the ANN technique. The analysis of profiles concludes that retrieved profiles using ANFIS techniques have improved the temperature retrievals substantially; however, the retrieval of RH by all techniques considered in this paper (ANN, MVLR and ANFIS) has limited success.

\section{Introduction}

Atmospheric convection plays an important role in the energy circulation of the atmosphere by transporting heat, momentum and moisture from the boundary layer to the free atmosphere. The vertical transport of these fluxes (heat, momentum and moisture) determines the evolution of multiscale convective phenomena such as thunderstorms and tornadoes (Lane and Moncrieff, 2010; Shaw and Lane, 2013). The temporal scale of these phenomena ranges from a few minutes to hours, and they are associated with disastrous effects that are of socioeconomic importance (Doswell III, 1985). Therefore, a continuous monitoring of the profiles of the atmosphere is important for their study. Conventionally, profiles of temperature and humidity are observed using radiosonde (GPS sonde hereafter referred to as radiosonde) measurements. However, it is difficult to study the evolution of convection using these observations due to their temporal resolution (frequency of vertical profiles). Further, these observations have a limited availability: operational radiosonde profiles are generally available at 00:00 and 12:00 UTC of every day as it is very expensive to launch radiosonde operationally at regular intervals of $1 \mathrm{~h}$. Therefore, it is difficult to monitor the convective systems which evolve during the 
interval in between these launches. Moreover, the network of radiosonde observations is spatially coarse, and many times convection may not occur where the radiosonde is flying. Sometimes, updrafts and downdrafts present in the convection cause either spatial drift of the radiosonde or the bursting of the rubber balloon. On the other hand, space-based measurements of vertical profiles of the atmosphere using radio and microwave radars or radiometers on low Earth-orbiting satellites, sun synchronous satellites or geostationary satellites are useful to identify the convections, their movement and evolution. However, their revisit time/frequency of the observations and limited retrieval skill in the lower part of the atmosphere does not allow investigating the genesis and evolution of convection in most of the cases.

In this situation, multichannel microwave radiometers (MWRs) have evolved as powerful tools for monitoring the genesis and evolution of the convection over a station (Chan, 2009). MWR enables continuously monitoring microwave brightness temperatures, from which temperature, relative humidity and liquid water content can be derived. There are many studies targeting the retrieval of temperature and humidity profiles using MWR (Waters et al., 1975; Pandey and Kakar, 1983; Rodgers, 2000; Ware et al., 2003; Löhnert et al., 2004; Rose et al., 2005; Knupp et al., 2009; Matzler and Morland, 2009; Löhnert and Maier, 2012; Stähli et al., 2013; Xu et al., 2014). These investigations are aimed at determining temperature and water vapour soundings by observing radiated power at different microwave frequencies. Snider and Hazen (1998) described the observations of water vapour and cloud liquid based on MWR at frequencies of 20, 23, 31 and $90 \mathrm{GHz}$. D'Auria et al. (1998) used 19,35 and $85 \mathrm{GHz}$ frequency observations to study cloud properties and to generate a database of cloud genera useful for radiative-transfer modelling. Westwater et al. (1998) deployed a scanning MWR operating at a frequency of $5 \mathrm{~mm}$ $(60 \mathrm{GHz})$ to study differences in boundary layer evolution over land and ocean. Their results showed the excellent agreement between atmospheric temperatures estimated by MWR and other measurements (meteorological towers and IR measurement). Ware et al. (2003) chose 12 microwave observation frequencies $(22.035,22.235,23.835,26.235,30.0$, $51.25,52.28,53.85,54.94,56.66,57.29$ and $58.8 \mathrm{GHz}$ ) to determine temperature, humidity and cloud liquid profiles. For these calculations the observed radiative power at different microwave frequencies converted into brightness temperatures using Plank's law. The profiles of temperature, relative humidity and liquid water content are retrieved using these brightness temperatures.

There are many retrieval algorithms proposed by previous investigators. Basili et al. (2001) developed a method to retrieve temperature profiles by microwave radiometry using a priori information on atmospheric spatial-temporal evolution. Bleisch et al. (2011) discussed the technique of the retrieval of water vapour profiles using MWR operating at a frequency of $22 \mathrm{GHz}$ and its application to retrieve humid- ity profiles in the upper troposphere and lower-stratospheric (UTLS) region. Cimini et al. (2003) discussed the performance, calibration and achievable accuracy of a set of four MWRs operating in the $20-30 \mathrm{GHz}$ band for the Atmospheric Radiation Program field experiments. They found that the brightness temperature measurements for two identical instruments differed less than $0.2 \mathrm{~K}$ over a period of $24 \mathrm{~h}$. Binco et al. (2005) have demonstrated the synergistic use of microwave radiometer profiles and wind profiler radar to retrieve atmospheric humidity. They used wind profiler radar to estimate the potential refractivity gradient profiles and optimally combined them with MWR-estimated potential temperatures in order to fully retrieve the humidity gradient profile. Their results showed the significant improvement in the spatial vertical resolution of the atmospheric humidity profilers. Iassamen et al. (2009) used 12 frequencies of MWR to analyse the statistical distribution of tropospheric water vapour content in clear and cloudy conditions. They found that, vertically integrated water vapour content follows a Weibull distribution. Also, the vertical profiles of water vapour content during clear and cloudy conditions are well described by a function of temperature of the same form as the Clausius-Clapeyron equation. Haobo et al. (2011) proposed a retrieval method for temperature and humidity profiles based on principal-component analysis and stepwise regression.

It is found from these studies that MWR is becoming a robust tool for the monitoring of brightness temperatures and retrieving temperature and humidity profiles and hence the thermodynamic conditions of the atmosphere, which are very important for studying convective storms (Chan, 2009; Cimini et al., 2011). Güldner and Spänkuch (2001) discussed remote sensing of the thermodynamic state of the atmospheric boundary layer using ground-based microwave radiometer. Chan (2009) discussed the use of an MWR thermodynamic profile for the nowcasting of severe weather, such as a rainstorm, using a humidity profile and $K$ index. They found that the accumulation of water vapour and the increase in the instability in the troposphere $1 \mathrm{~h}$ prior to occurrences of heavy rain are useful for its nowcasting. Therefore, MWR is becoming a useful tool for the nowcasting of intense convective weather due to high-frequency and accurate measurement of thermodynamical profiles. These profiles are very important for understanding the mesoscale processes and physical mechanisms involved in the preconditioning and triggering of small-scale convections such as thunderstorms and tornados. and also for understanding their temporal evolution. This understanding is very important for studying global energy transport. However, only limited efforts exist, especially over the tropical region because of the unavailability of high-frequency observations over this region.

Recent developments in the retrieval algorithms and computational techniques are adaptive and devise a model (Gaffard and Hewison, 2003) which improves the performance and accuracy of radiometer retrievals. Many nonlinear sta- 
tistical/evolutionary algorithms are being developed for retrieving the profiles of the atmosphere using MWR (Solheim et al., 1998). These include the artificial neural network (ANN), Newtonian iteration of statistically retrieved profiles and Bayesian most probable retrieval. ANNs are widely used for different types of infrared and microwave-sounding instruments (Frate and Schiavon, 1998; Binco et al., 2005). Frate and Schiavon (1998) presented an inversion technique to retrieve profiles of temperature and water vapour using MWR. Their techniques combined a profile over a complete set of orthogonal functions with ANN, which performs the estimate of the coefficient of the expansion itself. Their analysis shows that this technique is flexible and robust. Ajil et al. (2010) used a new nonlinear technique ANFIS (adaptive neuro-fuzzy inference system) to improve the first guess using simulated infrared brightness temperatures for Geostationary Operational Environmental Satellite (GOES)-12 sounder channels. They found that the results of ANFIS retrieval are robust and reduce the root mean squared error by $20 \%$ compared to regression fitting. They also argued that, as ANFIS uses a fuzzy-information system (FIS) for the classification of input, the classification of the training data set is not needed as it is required for regression techniques. In the present work, we have developed an ANFIS model-based retrieval of atmospheric parameters using MWR observations at NARL (National Atmospheric Research Laboratory), India. The objective of this algorithm development is to improve the accuracy of the retrieval of temperature and humidity profiles of MWR especially over the lower atmosphere.

The paper is organized as follows. Section 2 of this paper describes the details of data used for this study. The details of the method used and the ANFIS algorithm are described in Sect. 3. The experimental results are discussed in Sect. 4, and conclusions obtained from this work are presented in Sect. 5.

\section{Microwave radiometer}

The principal sources of atmospheric microwave emissions and absorptions are weak electric dipole rotational transition and magnetic dipole transitions of water vapour, oxygen and cloud liquid water (Westwater, 1993). Therefore, continuous monitoring of these thermal radiations has potential applications in meteorology and related sciences. MWRs are used for monitoring these radiations and are useful for continuous thermodynamical soundings (Ware et al., 2003). These MWRs are generally passive radiometers, continuously monitoring brightness temperature at various wavelengths in the microwave region of electromagnetic spectra. Ware et al. (2003) described the details of the MWR instrument, which is useful for temperature, water vapour and moisture sounding in clear and cloudy conditions. This instrument monitors the water vapour absorption line at $22 \mathrm{GHz}$ to determine the water vapour profile as the magnitude of pressure broadening of water vapour absorption line at this frequency decreases with height. This instrument monitors radiated power in a molecular oxygen absorption band around $60 \mathrm{GHz}$ to determine temperature profiles and radiative power at selected frequencies of 22 to $59 \mathrm{GHz}$ together to determine the liquid water profile. Cloud base height is estimated from zenith-infrared observations and retrieved temperature profiles. The MWR K band channels $(22-30 \mathrm{GHz})$ are calibrated using tipping and $\mathrm{V}$ band channels $(51-59 \mathrm{GHz})$ using a patented cryogenic black-body target. These calibrations are automatically transferred to a temperature-stabilized noise source. The internal mirror and azimuthal drive are used to point at any direction in the sky. The brightness temperatures are determined at various frequencies by using Plank's law and radiative-power observations (Han and Westwater, 2000; Ware et al., 2003). These brightness temperatures are used as input to the neural network for regression retrievals.

MWR is associated with the software (VIZMet-B)enabled ANN retrieval algorithm for retrieving the profiles of temperature, relative humidity, liquid water content and vapour density. This ANN is a simple back-propagation neural network developed by Stuttgart University. The backpropagation algorithm is trained using microwave radiances observed by MWR as inputs and corresponding radiosonde observations as outputs. ANN generated weighing functions corresponding to different microwave frequencies as required by a radiative-transfer model, which, in turn, is useful for deriving the height profiles of temperatures and relative humidity. This MWR provides data with a vertical resolution of $50 \mathrm{~m}$ from surface up to a height of $500 \mathrm{~m}, 100 \mathrm{~m}$ from $500 \mathrm{~m}$ to $2 \mathrm{~km}$ and $250 \mathrm{~m}$ from 2 to $10 \mathrm{~km}$. The further details of this MWR are available at the following website: http://www.radiometrics.com.

Gaffard and Hewison (2003), in their trial report on this radiometer (Radiometrics MP3000), have shown that the RMSE in the temperature profiles increases rapidly from $0.5 \mathrm{~K}$ at the surface to $1.5 \mathrm{~K}$ at $1 \mathrm{~km}$ and more slowly to $1.8 \mathrm{~K}$ at $5 \mathrm{~km}$. According to Cimini et al. (2006, 2010), temperature and humidity retrieval accuracy is best near the surface and degrades with height; also, above $3 \mathrm{~km}$, the retrieval accuracy and resolution degrade rapidly for all techniques. These studies used the observations reported without rain because the MWR cannot make any useful atmospheric observations during anything more than moderate rains. Thus, the major limitation of MWR is its performance degradation under heavy-precipitation conditions. Nevertheless, this instrument is believed to play an important role in investigating the thermodynamic condition of convection; however, the reliability and the performance can be enhanced by using better retrieval algorithms. Therefore, to improve/test the improvement of the accuracy of the retrieval of temperature and humidity profiles using MWR observations, we have developed the ANFIS system. 
(a)

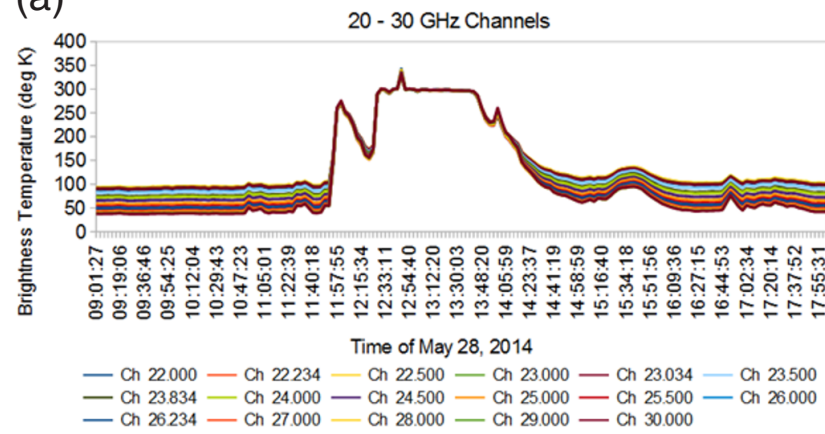

(c)

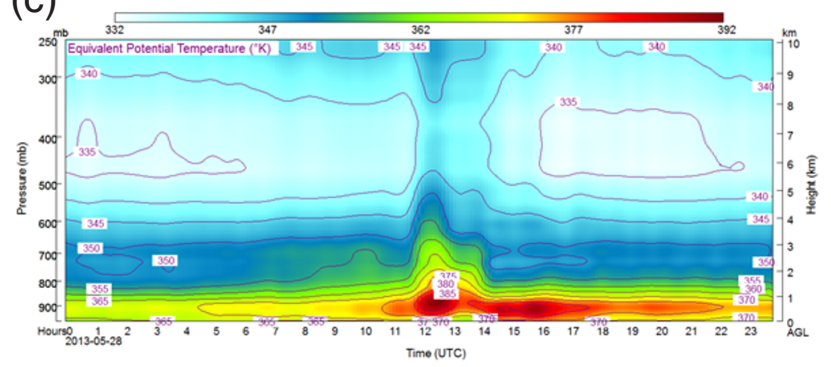

(e)

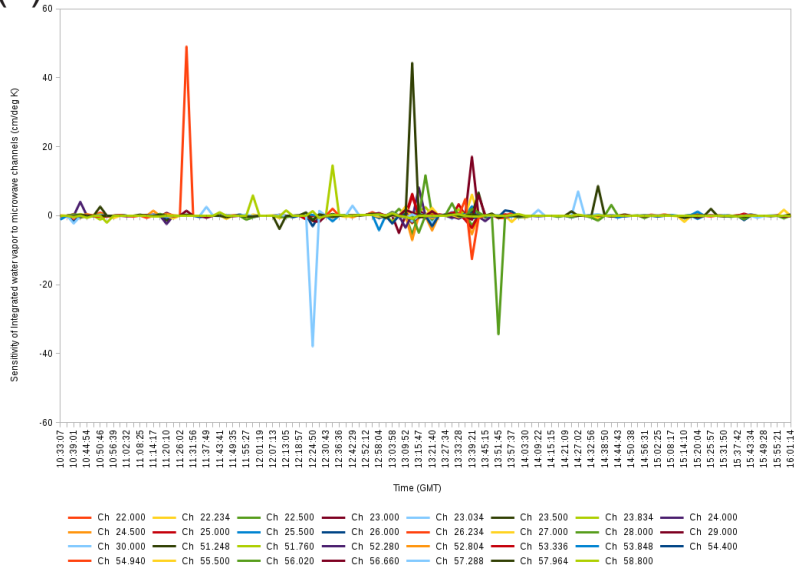

(b)

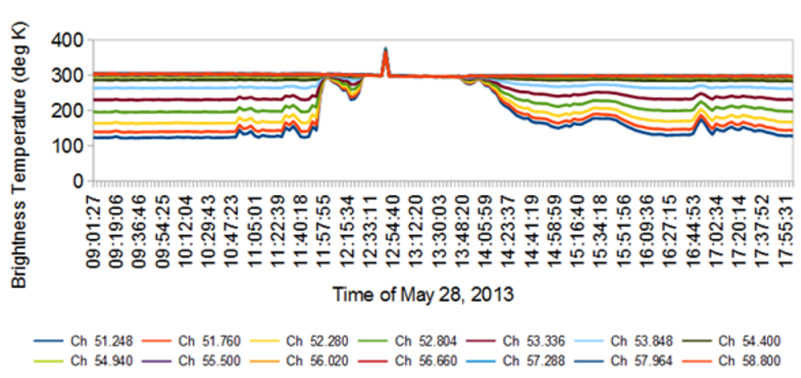

(d)

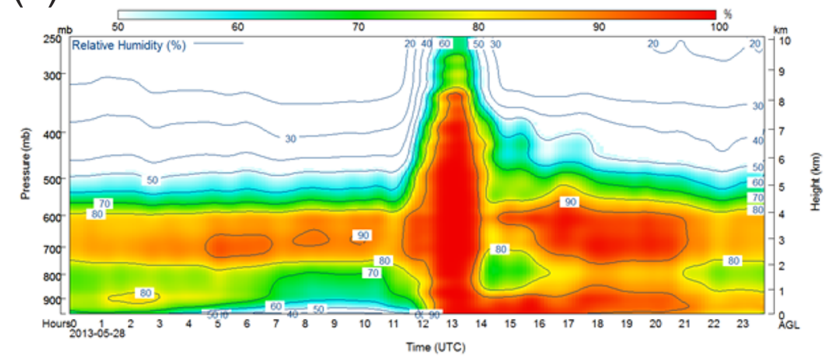

Figure 1. Sensitivity of 31 microwave brightness channels measured by MWR at (a) $20-30 \mathrm{GHz}$ and (b) $50-60 \mathrm{GHz}$ and the composite of vertical profiles of equivalent potential temperature (c) and relative humidity (d) retrieved during a convection event on 28 May 2013 over NARL Gadanki using MWR (ANN algorithm). The time resolution of these profiles is 4 min. (e) Sensitivities of integrated water vapour to brightness temperatures observed by MWR (rate of changes in integrated water vapour with respect to changes in brightness temperatures in each channel at a constant time span).

\section{Data}

At the National Atmospheric Research Laboratory, Gadanki $\left(13.5^{\circ} \mathrm{N}, 79.2^{\circ} \mathrm{E}\right)$, India, MWR (MP3000-A manufactured by M/S Radiometrics, USA) is installed to study diurnal variations in convection and rainfall, for which an understanding of the genesis and further evolution of convection is very important. MWR at NARL has 31 channels in the microwave frequency range of $20-200 \mathrm{GHz}$ ( 22 in $\mathrm{K}$ band and 14 in $\mathrm{V}$ band). For this study, we have used the observations from this MWR in zenith direction from 10 microwave channels, viz. $22.234,22.500,23.034,23.834,25.000,26.234,28.000$, $30.000,57.964$ and $58.800 \mathrm{GHz}$, to retrieve profiles of atmospheric temperature and relative humidity. These channels are selected based on the sensitivity of these channels during the occurrence of thunderstorms over the study site as shown in Fig. 1a and e. These figures show that these channels are sensitive to the advection of water vapour over this site (Fig. 1d) and its condensation during the period of $4 \mathrm{~h}$ prior to thunderstorm occurrence (Fig. 1c). Figure 1e shows the sensitivities of retrieved integrated water vapour content 
to microwave brightness temperatures at different frequencies.

For the formulation, training and validation of multivariate linear regression (MVLR), ANFIS and ANN systems, we have used the temperature and relative humidity observed by co-located GPS radiosonde (Meisei, Japan make, RS-01GII) measurements usually available almost every day at 12:00 UT $(\mathrm{LT}=\mathrm{UT}+05: 30 \mathrm{~h})$ at NARL Gadanki for the same period of training data set. Note that the Meisei radiosonde uses the temperature (relative humidity) sensors made with the thermistor (carbon humidity sensor), which measures the temperature (relative humidity) in the range of -900 to $+400{ }^{\circ} \mathrm{C}(0-100 \%)$ with an accuracy of 0.2 to $0.5^{\circ} \mathrm{C}(2-5 \%)$ (Basha and Ratnam, 2009).

In this work, we have used 122 days of MWR observations at the above-mentioned frequencies and radiosonde observations at 12:00 UTC during the period of JuneSeptember 2011. Out of 122 days (JJAS), 92 days are used for training the ANFISs (RD (rainy day) + NRD (non-rainy day)) and 30 days are used as an independent validation data set. The dates selected for independent validation are 24-30 June, 21-31 July, 26-31 August and 26-30 September 2011. ANFISs are trained using other 92-day observations excluding observations of the days selected for validation. Also, MVLR models are formulated using these 92-day observations and validated using the validation data set. The regular profiles of radiosondes are available every 12:00 UTC at the NARL site. Therefore, the ANFISs trained using 12:00 UTC observations. The ANFIS system would have been more robust if it had been trained using many radiosonde observations at regular intervals of each day. Unfortunately, obtaining periodic profiles of radiosondes at regular intervals of each day for long periods (monsoon months) to train the ANFIS system are not economically feasible. In this paper, for training and validation, we have sampled MWR data at 10 vertical locations at an interval of $1 \mathrm{~km}$ starting from $1 \mathrm{~km}$. The vertical resolution of radiosonde data available for this study during the observational campaign is of $100 \mathrm{~m}$ resolution; therefore, the radiosonde observations of temperature and relative humidity at an altitude of within $\pm 100 \mathrm{~m}$ of the target altitude are assumed at the sampled altitude.

\section{Method}

\subsection{Fuzzy-information system}

Fuzzy logic (FL) provides a simple way to arrive at a definite conclusion based upon vague, ambiguous, imprecise, noisy and missing input information (Priyono et al., 2005). Most of the FL models are empirically based, relying on an operator's experience rather than a technical understanding of the system. FL methods allow a number of inputs and generate a number of outputs. However, the generation of more inputs and outputs will create more rules, and their interrelations make models more complex. To avoid the subjectivity in the operator's experience, Takagi and Sugeno (1985; TS85) proposed a mathematical tool to build a fuzzy model of the system. The TS85 system is based on the fuzzy partition of the input space into fuzzy subspace and on generating a linear relationship between each fuzzy subspace. Thus it forms a multidimensional fuzzy set in the product space of input variables to identify the premise of the fuzzy rule and then assigns linear consequents of each rule (Priyono et al., 2005). The identification of the fuzzy model can be improved using multidimensional reference fuzzy sets. The model is then structured into a set of IF-THEN statements. The TakagiSugeno-Kang fuzzy model composed of IF-THEN rules is described by Priyono et al. (2005) and is described below.

$$
\begin{array}{r}
R_{(k)} \text { :If } x_{1} \text { is } A_{k}^{1} \text { and } x_{2} \text { is } A_{k}^{2} \text { and } \ldots \\
\text { and } x_{m} \text { is } A_{k}^{m} \text { then } y_{k} \text { is } f_{k}(x),
\end{array}
$$

where $f_{k}(x)=\alpha_{k}^{0}+\alpha_{k}^{1} x_{1}+\alpha_{k}^{2} x_{2}+\ldots+\alpha_{k}^{m} x_{m}$ is a linear function and

$-k=1 \ldots n$ denotes the node number

- $y_{k}=$ output variables

- $A_{k}^{m}=$ fuzzy sets (linguistic labels) associated with each node.

The above equation suggests that each fuzzy rule describes local linear behaviour. For any input $\hat{x}=\left(x_{k}^{1,} x_{k}^{2, \cdot} x_{k}^{m}\right)$ the inferred value of the Takagi-Sugeno-Kang (Takagi and Sugeno, 1985; Sugeno and Kang, 1988) fuzzy models is calculated as

$\gamma=\frac{\sum_{k=1}^{m} A_{k}(\hat{x})^{*}}{\sum_{k=1}^{m} A_{k}(\hat{x})}=\frac{\sum_{k=1}^{m} \tau_{k} \cdot f_{k}(\hat{x})}{\sum_{k=1}^{m} \tau_{k}}$,

where $A_{k}(\hat{x})=\tau_{k}=A_{k}^{1}\left(x_{k}^{1}\right) \cdot A_{k}^{2}\left(x_{k}^{2}\right) \cdot \ldots \cdot A_{k}^{m}\left(x_{k}^{m}\right), \tau_{k}$ is the level of firing of the kth rule for the current input $\hat{x}$. The model output is linear in weight but nonlinear in centre and standard deviation. The fuzzy clustering divides the input data space into fuzzy clusters, each representing one specific part of the system behaviour. There are several methodologies proposed for the clustering (Priyono et al., 2005). Chiu (1997, 1994) proposed the subtractive fuzzyclustering method, and it is described in detailed by Priyono et al. (2005). We have used this method to build the fuzzy rules. This helps in reducing the number of rules and automatically determining the number of clusters (Chiu, 1994). The number of fuzzy rules varies depending on the total number of clusters (Chiu, 1997; Yager and Filev, 1994). Subtractive clustering finds the high-density region in the feature space (Jang, 1997; Jang et al., 2007). Subtractive clustering identifies the cluster centre in the data points with the following procedure: 
1. Let $N$ be the number of data points with $n$ dimension vectors $x_{k}^{i} k=1,2, \ldots n i=1, \ldots m$.

2. Density measure is calculated for each data point. A density measure at data point $x_{k}^{i}$ is

$$
D_{k}^{i}=\sum_{j=1}^{n} \exp \left(\frac{\left\|x_{k}^{i}-x_{j}^{i}\right\|^{2}}{\left(\frac{r_{a}}{2}\right)}\right),
$$

where $r_{a}$ is the radius of the cluster. We have set its value to 0.3 in this analysis.

3. Based on the density measure, the data point with the highest density is selected as the first cluster centre $x_{c 1}$, with a density measure of $D_{c 1}$.

4. The density measure for each data point is revised by

$$
D_{k}^{i}=D_{k}^{i}-D_{c 1}^{i} \sum_{j=1}^{n} \exp \left(\frac{\left\|x_{k}^{i}-x_{j}^{i}\right\|}{\left(\frac{r_{b}}{2}\right)^{2}}\right) .
$$

The constant $r_{b}$ defines a neighbourhood to be reduced in density measure. To avoid repetition in the data points within the selected cluster, the data points within the cluster are discarded, and their absence is ensured in the next cluster. With the new feature space, a new highdensity point is identified by the algorithm. This procedure is continued until all the data points are evaluated. Finally, the algorithm returns a set of clusters based on the Euclidean distance between the cluster centre and the data point (search radius).

\subsection{ANFIS}

ANFIS is a hybrid learning procedure which constructs an input-output mapping based on fuzzy if-then rules with appropriate member functions to generate the stipulated inputoutput pairs (Jang, 1993). ANFIS exploits the machinelearning potential of ANN and multi-valued logic of a fuzzy system in a single framework. Fuzzy logic is used for the classification of an input data set in different classes and forms the input to artificial neural networks. Then ANN is used to predict the output based on the training data sets. Thus, fuzzy logic controls the way of processing data by its classification to minimize the error in the neural network prediction (Tahmaseb and Hezarkhani, 2010). In recent decades, the ANFIS system has been used for many applications, such as turning tool-failure detection (Lo, 2002), quantitative structure activity relationships (Buyukbingol et al., 2007), drought forecasting (Bacanli et al., 2009), sea level prediction (Lin and Chang, 2008) and grade estimation (Tahmaseb and Hezarkhani, 2010). ANFIS caters to the need of complex real-world problems, which require intelligent systems that combine knowledge, techniques and methodologies from various sources.
In this work, the ANFIS is used with 10 predictors (brightness temperatures of 10 channels observed by MWR as mentioned above) as input to retrieve the temperature and humidity each at 10 sampled altitudes, i.e. to determine 20 outputs. This means output parameters are correlated in some fashion. We have used a Sugeno-type subtractive fuzzy clustering (Chiu, 1994) to reduce the number of predictors to decrease the training rule in FIS to make ANFIS more robust. The reduction in the number of rules automatically determines the number of clusters by assuming each data point as a potential cluster centre and creates clusters based on the density (Chiu, 1994). We found that subtractive-type clustering forms six rules for retrieval of temperature and seven rules for retrieval of $\mathrm{RH}$ with number of degrees of freedom equal to four and three respectively. The ANFIS model structure used in this work is shown in Fig. 2 and described in the next session.

\subsection{ANFIS model structure}

In this work, to profile the vertical distribution of temperature and relative humidity, a separate ANFIS model is developed for each level starting from 1 to $10 \mathrm{~km}$ with a vertical resolution of $1 \mathrm{~km}$. Each ANFIS model in this work uses tier-3 architecture (Fig. 2) based on the fuzzy set if-then rules proposed by Takagi and Sugeno (1983). It comprises of five layers viz. input layer, input membership functions, rules, output membership functions and output. Layer 0 of this model passes the input to all membership functions by using the observed brightness temperature at 10 different microwave frequencies at each height level as mentioned earlier (i.e. $m=10$ ). Layer 1 is known as the fuzzification layer, in which the input values of brightness temperatures $(x)$ are normalized with a maximum equal to 1 and a minimum equal to 0 . This layer uses Gaussian function for normalization. This process is termed fuzzification and each node $k$ associated with the membership function $O_{k}^{1}$.

$O_{k}^{1}=\mu A_{k}\left(x_{k}\right)$

As discussed earlier, $x_{k}$ is the input, $A_{k}$ are the linguistic labels associated with the membership function and $\mu A_{k}$ is a Gaussian function written as

$\mu A_{k}\left(x_{k}^{i}\right)=\exp \left[-\left(\frac{x_{k}^{i}-b_{k}}{a_{k}}\right)^{2}\right]$,

where, $a_{k} b_{k}$ are model parameters determined quantitatively and responsible for variation in the shape of input membership functions.

Layer 2 multiplies input signals and sends product out. The node in layer 2 is the product of the degrees to which the inputs satisfy the membership functions, and it is found by

$w_{k}=\Pi \mu A_{k}\left(x_{k}\right), k=1, \ldots n$.

Layer 3 is the normalization layer in which the ratio of each rule's firing strength is calculated with respect to the sum of 


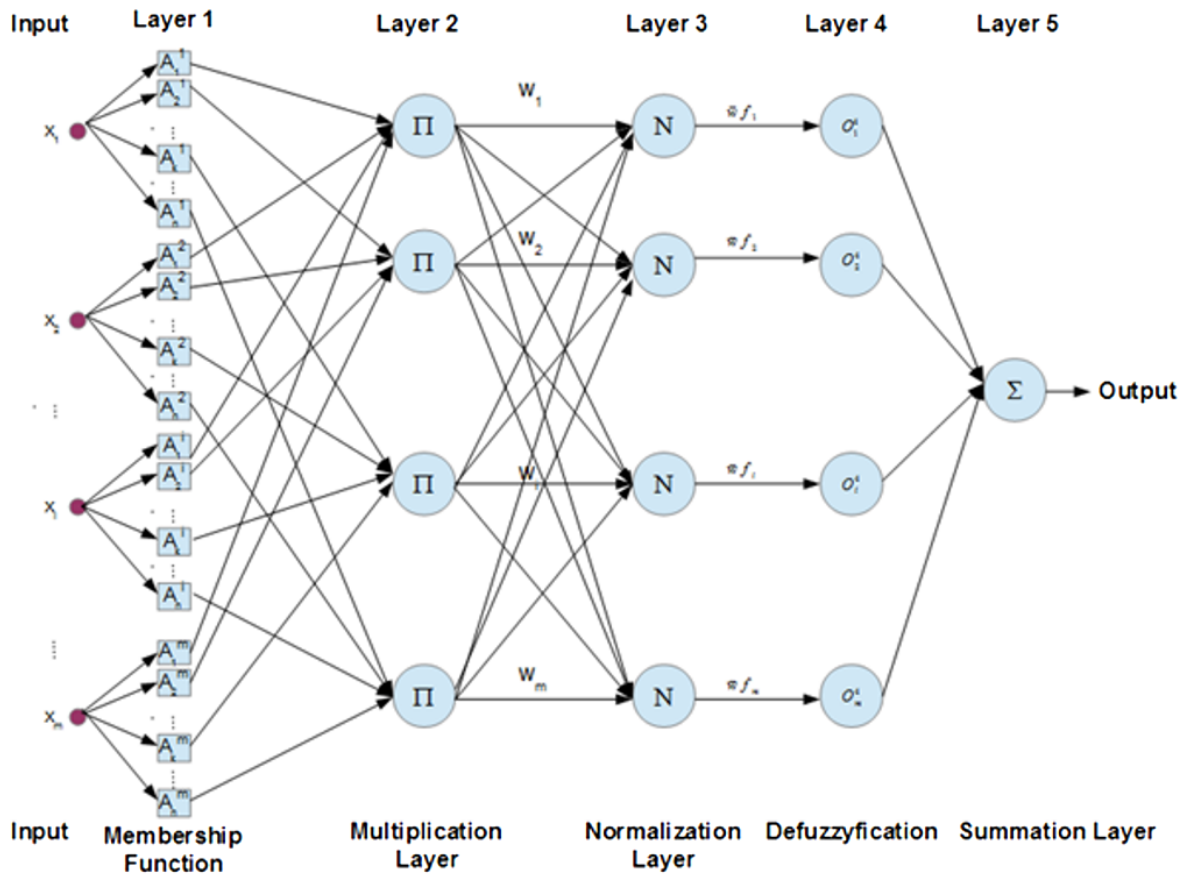

Figure 2. An ANFIS architecture for the Sugeno system used in this study (where $m=10, n=2, i=1,2$ and $k=1,2, \ldots, 10$ ).

the firing strengths of all the rules.

$\bar{w}_{k}=\frac{w_{k}}{\sum_{k=1}^{n} w_{k}}$

The output of each node in layer 4 (defuzzification layer) is the weighted consequent value, and it is calculated by

$O_{i}^{4}=\bar{w} f_{k}=\bar{w}_{k}\left(\alpha_{k}^{0}+\alpha_{k}^{1} x_{1}+\ldots+\alpha_{k}^{m} x_{m}\right)$,

where $\alpha_{k}^{i}$ is the parameter set.

Layer 5 is the summation layer, and its output is the sum of all the outputs of layer 4 .

$O_{5,1}=\sum_{k=1}^{n} \bar{w}_{k} f_{k}=\frac{\sum_{k=1}^{n} w_{k} f_{k}}{\sum_{k=1}^{n} w_{k}}$

In this analysis, the FIS has been generated using the function genfis2 in MATLAB.

We have trained the ANFIS system in two ways: (1) by considering rainy days in the training data set and (2) by not considering rainy days in the training data sets. In this paper we have used ANFIS(NRD) to refer to ANFIS trained using microwave brightness temperature inputs only on non-rainy days and ANFIS(RD + NRD) to refer to ANFIS trained using microwave brightness temperature inputs on rainy and non-rainy days observed during the training period. The fitness of both the ANFIS and ANN models is tested as described below.

\subsection{Multivariate linear regression}

Multivariate linear regression (MVLR) is a classical linear statistical forecasting tool for understanding the relationship between a dependent variable and two or more independent variables. The multiple regression technique formulates a model to obtain estimates of the values of the dependent variable by fitting a linear equation to observed variables. Generally the form of the regression model is expressed as follows:

$y_{i}=\beta_{0}+\sum_{p=1}^{n} \beta_{p} x_{i p}+\epsilon_{i}$ where $i=1,2, \ldots m$,

where $y_{i}$ is a dependent variable which needs to be predicted (temperature and $\mathrm{RH}$ at different heights), $x_{i p}$ is an independent variable (brightness temperatures measured by MWR at 10 different frequencies as mentioned above), $\beta_{p}$ is a coefficient of linear regression which measures changes in $y_{i}$ with respect to $x_{i p}, \varepsilon_{i}$ is an error term representing the collective unobserved influence of any omitted variables, $m$ is the number of in dependent variables, i.e. 10 in this paper, and $n$ is the number of days used for training, i.e. 92 (total of 122 days of the months June to September 2011 - 30 days for independent verification) in this paper. Tables $1 \mathrm{a}, \mathrm{b}$ and $2 \mathrm{a}, \mathrm{b}$ list the values of $\beta_{p}$ for temperature and $\mathrm{RH}$ profiles for $\operatorname{MVLR}(\mathrm{RD}+\mathrm{NRD})$ and MVLR(NRD) respectively. In this paper, we have compared ANFIS(RD + NRD) and ANFIS(NRD) retrievals of profiles of temperature and $\mathrm{RH}$ with predicted profiles using MVLR. The results are discussed in the next section. 
(a)
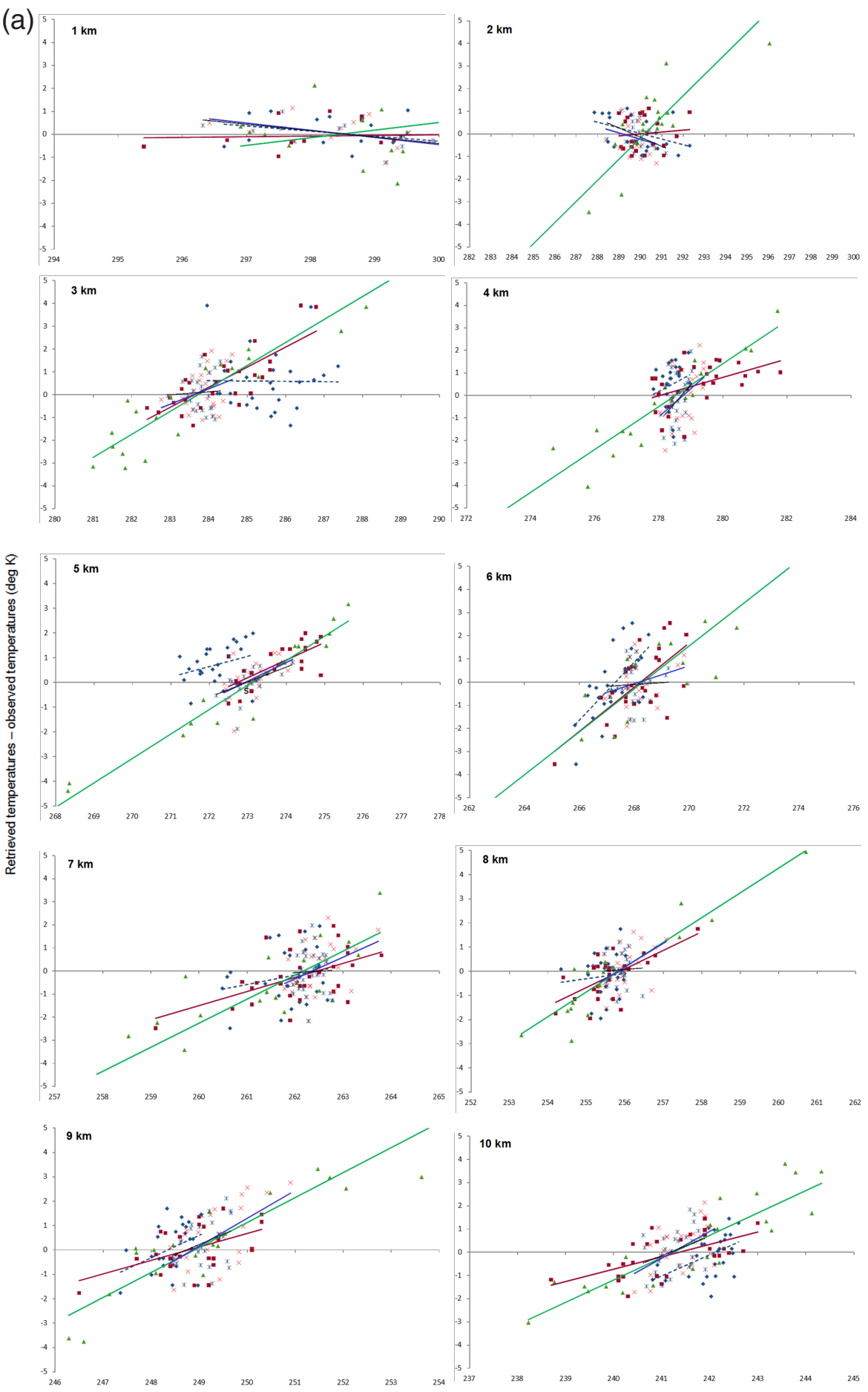

$10 \mathrm{~km}$

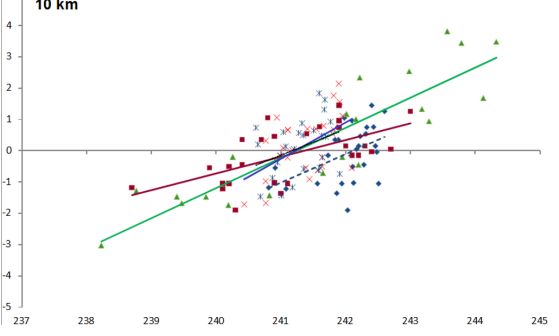

Retrieved temperatures (deg K)

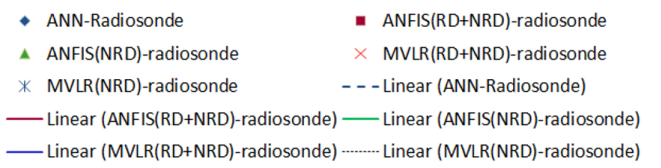

Figure 3. 

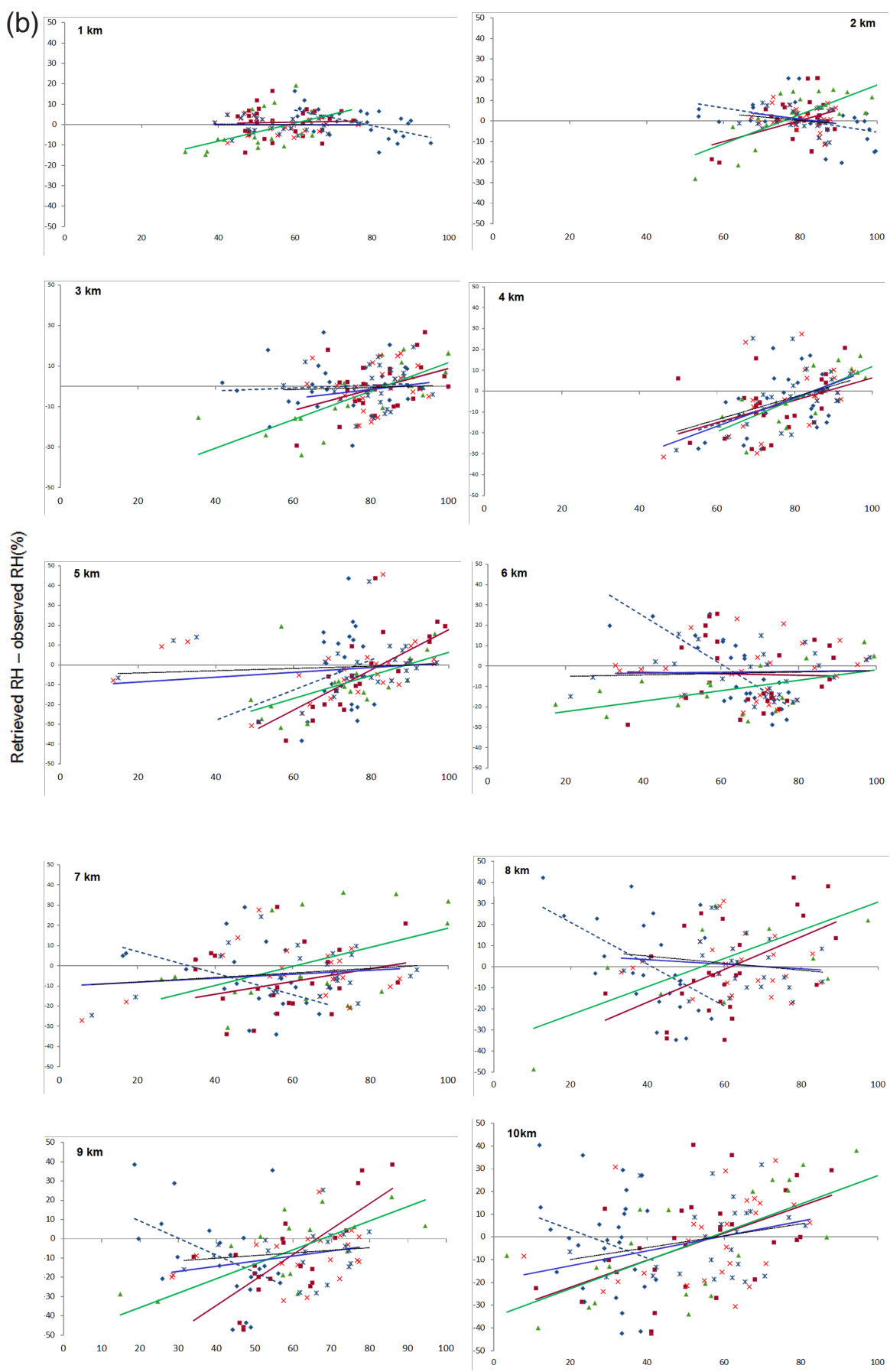

Retrieved RH (\%)

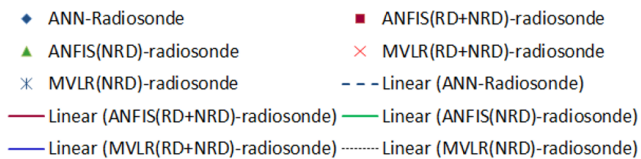

Figure 3. 
Table 1a. Multivariate regression coefficients and intercepts for temperature approximation at different height levels. Coefficients are derived using rainy and non-rainy days data.

\begin{tabular}{lrrrrrrrrrr}
\hline & \multicolumn{10}{c}{ Height $(\mathrm{km})$} \\
\cline { 2 - 11 } MVLR coefficients & 1 & 2 & 3 & 4 & 5 & 6 & 7 & 8 & 9 & 10 \\
\hline Intercept & 76.27 & 180.98 & 273.72 & 303.64 & 283.82 & 238.34 & 238.05 & 217.77 & 176.39 & 171.46 \\
22.23 & -0.16 & 0.16 & 0.26 & 0.25 & 0.52 & 0.29 & 0.57 & 1.00 & 0.81 & 0.60 \\
22.5 & 0.54 & 0.06 & -0.05 & -0.57 & -0.35 & -0.34 & -0.45 & -0.69 & -1.19 & 0.14 \\
23.03 & -0.60 & -0.55 & -0.39 & -0.20 & -0.86 & -0.58 & -0.60 & -0.56 & -0.18 & -0.46 \\
23.83 & 0.08 & 0.17 & 0.59 & 0.66 & 0.70 & 0.56 & 0.33 & -0.02 & 1.22 & -0.74 \\
25 & 0.29 & 0.31 & -0.53 & 0.14 & 0.20 & 0.19 & 0.70 & 0.74 & -0.19 & 0.48 \\
26.23 & -0.11 & 0.37 & -0.32 & 0.02 & 0.46 & 0.28 & -0.46 & -0.25 & -0.84 & -0.01 \\
28 & 0.11 & -0.34 & 0.77 & -0.44 & -0.91 & -0.15 & -0.15 & -0.47 & 0.20 & -0.05 \\
30 & -0.14 & -0.12 & -0.32 & 0.14 & 0.26 & -0.22 & 0.06 & 0.28 & 0.19 & 0.04 \\
57.96 & 0.13 & 0.00 & 0.00 & 0.11 & -0.03 & 0.01 & -0.10 & -0.04 & -0.18 & 0.03 \\
58.8 & 0.61 & 0.36 & 0.04 & -0.19 & 0.00 & 0.10 & 0.19 & 0.17 & 0.41 & 0.20 \\
\hline
\end{tabular}

Table 1b. Same as Table 1a but for relative humidity.

\begin{tabular}{|c|c|c|c|c|c|c|c|c|c|c|}
\hline \multirow[b]{2}{*}{ MLR coefficients } & \multicolumn{10}{|c|}{ Height (km) } \\
\hline & 1.00 & 2.00 & 3.00 & 4.00 & 5.00 & 6.00 & 7.00 & 8.00 & 9.00 & 10.00 \\
\hline Intercept & 1364.58 & 545.24 & -366.83 & -532.92 & 63.44 & 720.22 & 196.00 & 856.69 & 688.20 & 811.07 \\
\hline 22.23 & -0.66 & -3.92 & -7.57 & 3.19 & -4.87 & 7.27 & 6.43 & -3.12 & -5.39 & 1.46 \\
\hline 22.50 & -2.47 & 1.77 & 4.45 & 0.87 & 2.83 & -9.07 & 9.03 & 12.32 & 20.06 & 8.33 \\
\hline 23.03 & 2.22 & 4.15 & 3.49 & -5.72 & 10.60 & 13.18 & -5.21 & 3.23 & -6.83 & 0.04 \\
\hline 23.83 & 1.09 & -1.36 & -3.17 & 8.57 & -3.62 & -10.66 & -12.02 & -17.04 & -9.83 & -11.36 \\
\hline 25.00 & 1.28 & 0.39 & 8.38 & -0.29 & 2.32 & 4.99 & -6.03 & -2.70 & -10.17 & -6.24 \\
\hline 26.23 & 3.13 & -0.72 & 4.38 & -8.46 & -14.74 & -15.01 & 7.93 & 5.35 & 15.11 & 2.82 \\
\hline 28.00 & -4.25 & -1.34 & -14.23 & -3.42 & -2.08 & 3.62 & -3.07 & 6.36 & 1.22 & 11.45 \\
\hline 30.00 & 0.08 & 1.20 & 5.06 & 5.81 & 9.47 & 5.59 & 2.97 & -4.09 & -3.79 & -6.32 \\
\hline 57.96 & -0.95 & 0.21 & 2.43 & 2.03 & 0.88 & -5.99 & 5.07 & -0.61 & 1.74 & 2.53 \\
\hline 58.80 & -3.55 & -1.93 & -1.32 & -0.54 & -1.52 & 3.33 & -5.85 & -2.30 & -4.04 & -5.24 \\
\hline
\end{tabular}

\section{Results and discussions}

\subsection{MWR observations during convection}

Figure 1a-e show the evolution of thunderstorm observed continuously (temporal resolution of temperature and relative humidity (RH) profiles: $4 \mathrm{~min}$ ) by MWR on 28 May 2013. Figure 1a-b show the time series of different microwave channels at different frequencies between 20-30 and $50-60 \mathrm{GHz}$ respectively. It can be seen from these figures that there is an increase in the magnitudes of brightness temperatures about $3 \mathrm{~h}$ prior to the occurrence of a thunderstorm. Therefore, the observed profiles of equivalent potential temperatures indicate preconditioning of the vertical column of the atmosphere to be conducive to the occurrence of thunderstorms about 3-4h prior to their actual occurrence (Fig. 1c). The profile of relative humidity indicates the horizontal advection of moisture in a layer between $800-600 \mathrm{hPa}$ and uplifting of moisture about $4 \mathrm{~h}$ prior to the occurrence of a thunderstorm. Therefore, MWR is found useful for in- vestigating the genesis and behaviour of the convection. The different microwave channel sensitivities to integrated water vapour content over the site of MWR are shown in Fig. 1e. As seen from this figure, different microwave frequencies are sensitive to changes in the water vapour content of the atmosphere. Figure 1a-e indicate that microwave brightness temperature observations can be used as a predictor for retrieving high-frequency profiles of relative humidity, and temperatures provided robust, reliable and accurate algorithms. In recent decades, ANFIS has been used for many applications, as mentioned above, because FIS trains back-propagation neural networks for different sets of input classification to generate robust results.

\subsection{ANFIS training phase}

The temperature and humidity profiles retrieved from ANFIS models for the training period are compared with the profile derived from GPS radiosonde observations. (Figure is not shown in the paper.) It is observed that during the 

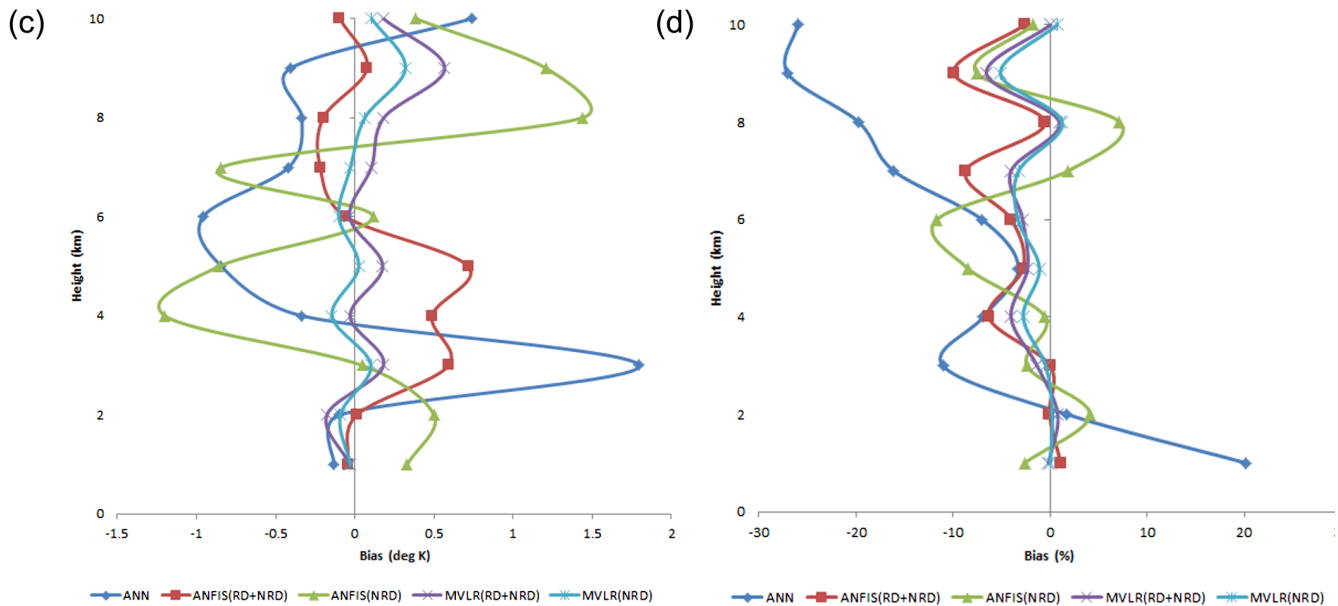

Figure 3. Scatter plot of difference between retrieved values of (a) temperature and (b) relative humidity using ANN, ANFIS(RD + NRD), ANFIS(NRD), MVLR(RD + NRD) or MVLR(NRD) techniques with radiosonde observations versus the retrieved values using these techniques respectively. Panels (c) and (d) are vertical distributions of bias in retrievals by different techniques for temperature and RH respectively.

Table 2a. Multivariate regression coefficients and intercepts for temperature approximation at different height levels. Coefficients are derived using only non-rainy days data.

\begin{tabular}{lrrrrrrrrrr}
\hline & \multicolumn{10}{c}{ Height $(\mathrm{km})$} \\
\cline { 2 - 11 } MLR coefficients & 1 & 2 & 3 & 4 & 5 & 6 & 7 & 8 & 9 & 10 \\
\hline Intercept & 66.18 & 177.71 & 280.74 & 317.54 & 293.35 & 246.38 & 246.26 & 225.88 & 199.99 & 182.26 \\
22.23 & -0.06 & 0.43 & -0.06 & -0.13 & -0.10 & -0.10 & 0.02 & 0.55 & 0.09 & 0.52 \\
22.5 & 0.34 & -0.47 & 0.17 & 0.11 & 0.50 & 0.01 & 0.22 & -0.09 & -0.42 & 0.12 \\
23.03 & -0.46 & -0.22 & -0.17 & -0.19 & -0.95 & -0.19 & -0.57 & -0.58 & 0.11 & -0.51 \\
23.83 & 0.06 & 0.08 & 0.29 & 0.18 & 0.50 & 0.04 & 0.24 & -0.10 & 0.66 & -0.46 \\
25 & 0.18 & 0.37 & -0.35 & 0.16 & 0.22 & 0.40 & 0.42 & 0.37 & -0.27 & 0.30 \\
26.23 & 0.01 & 0.28 & -0.17 & -0.05 & 0.37 & 0.26 & -0.33 & -0.13 & -0.56 & 0.05 \\
28 & 0.19 & -0.18 & 0.73 & 0.00 & -0.66 & -0.25 & 0.13 & 0.03 & 0.61 & 0.16 \\
30 & -0.22 & -0.22 & -0.43 & -0.09 & 0.13 & -0.14 & -0.12 & -0.05 & -0.19 & -0.17 \\
57.96 & 0.20 & 0.01 & 0.00 & 0.07 & 0.12 & 0.23 & 0.07 & 0.22 & -0.02 & 0.05 \\
58.8 & 0.57 & 0.36 & 0.00 & -0.20 & -0.18 & -0.15 & -0.01 & -0.12 & 0.18 & 0.15 \\
\hline
\end{tabular}

training period the values of the RMSE of temperature and relative humidity profiles are less than $0.01^{\circ} \mathrm{C}$ and $0.01 \%$ respectively for all heights. The decrease in RMSE values regarding both $\mathrm{RH}$ and temperature retrieval are observed at heights of 2, 4 and $8 \mathrm{~km}$ for temperature retrieval. Similarly, for an $\mathrm{RH}$ profile there is a decrease in the RMSE values at 2, 6 and $9 \mathrm{~km}$ during the training period. It is seen that the number of radiosonde observations within $100 \mathrm{~m}$ of these sampled altitudes is higher compared to other altitudes. The decrease in the values of RMSE at this altitude may be due to the availability of relatively more samples for training. In general, it is found that, during the training phase, the ANFIS model shows a very good fit to radiosonde observations. Therefore, it is worth testing this model using an independent data set which is not considered for the training as discussed in Sect. 2.

\subsection{Bias and scatter plots analysis}

Figure $3 \mathrm{a}$ and $\mathrm{b}$ show the scatter plots between radiosonde observations and ANFIS(NRD), ANFIS(RD + NRD), MVLR(RD + NRD), MVLR(NRD) and ANN retrievals of temperature and relative humidity for different heights. The vertical profile of the bias in temperature and $\mathrm{RH}$ profiles is shown in Fig. 3c-d. It is seen from these figures that there is a significant reduction in the value of the bias for ANFIS(RD + NRD) and MVLR(RD + NRD) retrieval algorithms compared to MVLR(NRD), ANN and ANFIS(NRD) algorithms. However, it is seen from the analysis that ANN has relatively more systematic bias compared to ANFIS algorithms. More investigation in terms of the optimal amount of input data required for the appropriate classification using FIS and training of neural network is needed and is the aim of another publication. 
Table 2b. Same as Table 2a but for relative humidity.

\begin{tabular}{|c|c|c|c|c|c|c|c|c|c|c|}
\hline \multirow[b]{2}{*}{ MLR coefficients } & \multicolumn{10}{|c|}{ Height (km) } \\
\hline & 1 & 2 & 3 & 4 & 5 & 6 & 7 & 8 & 9 & 10 \\
\hline Intercept & 1451.02 & 575.59 & -557.29 & -833.55 & -304.23 & 920.46 & 660.87 & 973.55 & 370.93 & 517.24 \\
\hline 22.23 & -0.73 & -4.98 & -2.47 & 5.02 & 2.49 & 3.83 & 5.51 & 1.20 & 3.97 & 4.90 \\
\hline 22.50 & -2.34 & 4.47 & -0.09 & -3.84 & -2.92 & -1.98 & 8.46 & 7.76 & 13.71 & 4.98 \\
\hline 23.03 & 2.31 & 1.58 & 2.01 & -2.20 & 5.20 & 8.20 & -2.99 & 2.69 & -12.42 & 1.06 \\
\hline 23.83 & 0.79 & -0.14 & -0.22 & 9.07 & 3.21 & -7.25 & -12.27 & -16.59 & -7.49 & -17.23 \\
\hline 25.00 & 1.67 & -0.21 & 7.45 & -3.01 & -2.06 & 0.27 & -5.19 & -0.96 & -8.32 & 2.01 \\
\hline 26.23 & 2.02 & 0.01 & 0.59 & -5.74 & -14.80 & -13.06 & 3.54 & 4.12 & 15.94 & 3.99 \\
\hline 28.00 & -3.25 & -1.79 & -12.13 & -5.59 & 2.11 & 5.26 & -1.03 & 5.09 & -5.54 & 2.89 \\
\hline 30.00 & -0.10 & 1.22 & 5.59 & 6.87 & 6.82 & 4.53 & 3.75 & -3.00 & 0.49 & -2.35 \\
\hline 57.96 & -1.71 & 0.36 & 2.01 & 0.37 & 0.93 & -3.58 & 1.63 & -3.02 & 0.32 & 1.55 \\
\hline 58.80 & -3.06 & -2.16 & -0.27 & 2.09 & -0.26 & 0.28 & -3.92 & -0.27 & -1.53 & -3.32 \\
\hline
\end{tabular}

(a)

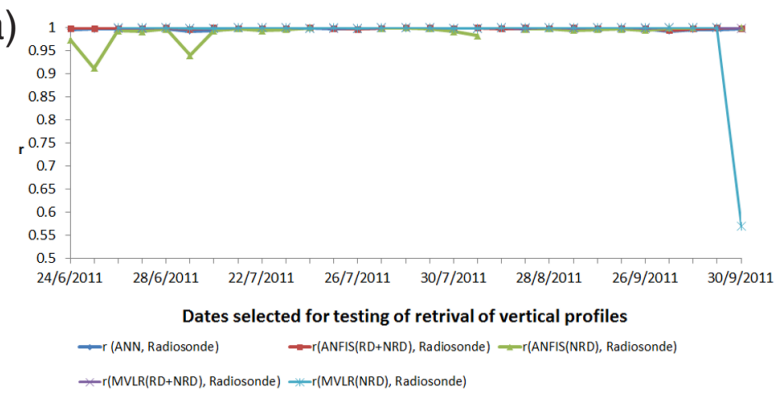

(b)

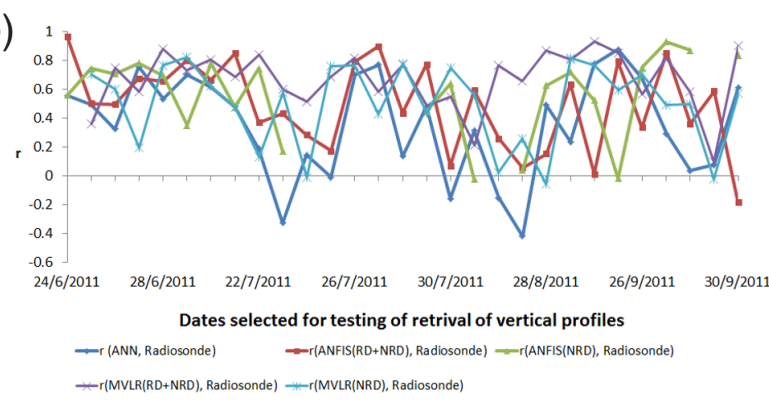

Figure 4. Pearson product movement correlation coefficient $(r)$ between radiosonde (a) temperature and (b) humidity profiles with retrieved profiles using ANN, ANFIS(RD + NRD), ANFIS(NRD), $\operatorname{MVLR}(R D+N R D)$ and MVLR(NRD).

\subsection{Correlation between retrieved and radiosonde profiles}

The values of $r$ calculated for the dates selected for the testing of retrieved profiles are shown in Fig. $4 \mathrm{a}$ and $\mathrm{b}$. The $r$ values for the temperature retrieval are more than 0.99 for ANN and ANFIS(RD + NRD) algorithms, and the value is relatively less for ANFIS(NRD) but better than 0.92. This indicates that these algorithms are successful in retrieving temperature profiles. It is also seen from Fig. 4a that the performance of ANFIS(RD + NRD) for temperature retrieval is slightly better compared to the other two algorithms. Therefore it may be stated that the retrieval of temperature profiles using ANFIS(RD + NRD) is more reliable and can be used for the investigation of the physical mechanism associated with tropical convective systems. However, the retrieval of $\mathrm{RH}$ is also very important for investigating different microphysical processes responsible for the convection. Figure $4 \mathrm{~b}$ shows the values of $r$ for RH retrieval. One of the limitations of radiosonde observations is that the radiosonde drifts far away due to heavy winds during dynamical weather conditions when, generally, the atmosphere is moist and cloudy. Therefore, the data set of RH may not represent true measurements above the region zenith of the MWR as RH has more spatial variability than temperature. Also, there is limited information content in the brightness temperatures for the vertical distribution of moisture. Therefore, it is difficult to correlate the RH-retrieved profiles with that observed with radiosonde measurements. Nevertheless, the values of $r$ are more than $60 \%$ for about 18, 13 and 9 cases out of 29 cases for the ANFIS(RD + NRD), ANFIS(NRD) and ANN algorithms. For the rest of the cases, the values of $r$ are less than $60 \%$. In the case of the ANN(ANFIS) retrieval of RH, it is found that 4 (1) case(s) out of 29 cases are negatively correlated with the radiosonde measurements. Thus, we found that the retrieval of RH using ANFIS(RD + NRD) is comparatively better than that of other two algorithms. However, we believe that a detailed investigation is required to understand and improve the correlation between $\mathrm{RH}$ radiosonde profiles and retrieved profiles, especially in the cloudy atmosphere or convectively efficient environment. It is worth investigating the impact of clouds on MWR brightness temperatures and consequently the retrieval of the humidity profile. This requires understanding the environmental dependence of the brightness temperatures measured by MWR. The adaptive virtue of ANFIS makes them suitable for further improvement of the retrieval technique presented in this paper, with the above-mentioned considerations. However, we strongly 

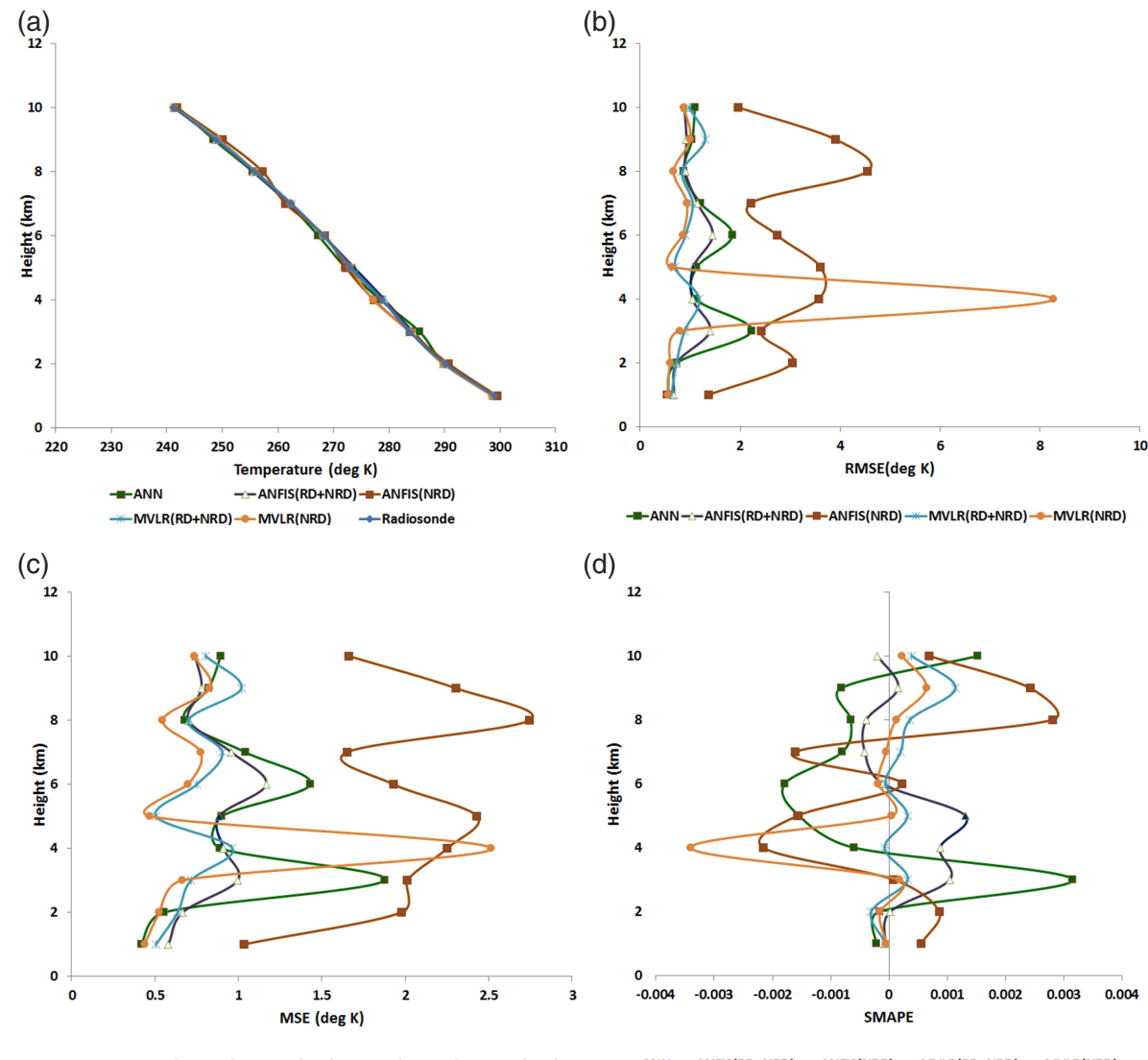

Figure 5. Comparison of vertical profiles of (a) temperatures observed by radiosonde and temperature profiles retrieved from ANN ANFIS(RD + NRD), ANFIS(NRD), MVLR(RD + NRD) and MVLR(NRD) and (b) RMSE, (c) MAE and (d) SMAPE of retrieved profiles using ANN ANFIS(RD + NRD), ANFIS(NRD), MVLR(RD + NRD) and MVLR(NRD) with respect to temperature profiles observed by radiosonde.

feel that more systematic investigation is required to understand it, and we think that it should be addressed in another publication rather than in this paper.

\subsection{Error analysis of retrieved temperature profiles}

Figure 5a-d show the mean vertical profiles obtained by radiosonde profiles and retrieved from ANFIS(RD + NRD), ANFIS(NRD), MVLR(RD + NRD), MVLR(NRD) and ANN techniques. As mentioned in the previous section, it is seen from Fig. 5a that the mean (30 hypothesis testing days) observed and retrieved profiles overlap and have relatively very less errors. The RMSE for the verification data set is less than $0.7^{\circ} \mathrm{C}$ up to $2 \mathrm{~km}$ and shows a slight increase of 1 to $2.3^{\circ} \mathrm{C}$ at higher heights (Fig. 5b). The average error is $1.08^{\circ} \mathrm{C}$. The profile of RMSE shows a small warm bias in the retrieved values of temperatures using the ANFIS(RD + NRD) model. However, ANFIS(RD + NRD) shows a significant reduction in bias and relatively better performance as compared to other two algorithms. The mean absolute error (MAE) for the test data set follows the qualitative trend of RMSE but is slightly less in magnitude.
The ANFIS(RD + NRD) algorithm has relatively less MAE. The behaviour of the symmetric mean absolute percentage error (SMAPE) (Fig. 5d) suggests that ANFIS(NRD) considers relatively more variation in temperature compared to the ANFIS(RD + NRD) and ANN algorithms and has a positive bias below $3 \mathrm{~km}$ and above $6 \mathrm{~km}$ and a negative bias in between 3 and $6 \mathrm{~km}$.

Venkat Ratnam et al. (2013) have compared GPS radiosonde profiles with retrieved profiles using the ANN algorithm available with MWR (ANN-MWR). Their results showed that the warm (cold) bias between radiosonde and MWR in temperature is clearly observed below (above) 3 $4 \mathrm{~km}$ depending upon the time. Madhulatha et al. (2013) have studied the mean profiles for temperature and vapour density and the difference between temperatures and vapour density along with standard deviations derived from ANN-MWR and a GPS radiosonde for the period June through December 2011. They found a very close agreement in temperature profiles between MWR and GPS radiosonde. Their results show differences in retrieved profiles with an ANN-MWR cold bias of about $2{ }^{\circ} \mathrm{C}$ up to $4 \mathrm{~km}$ and a warm bias of about 

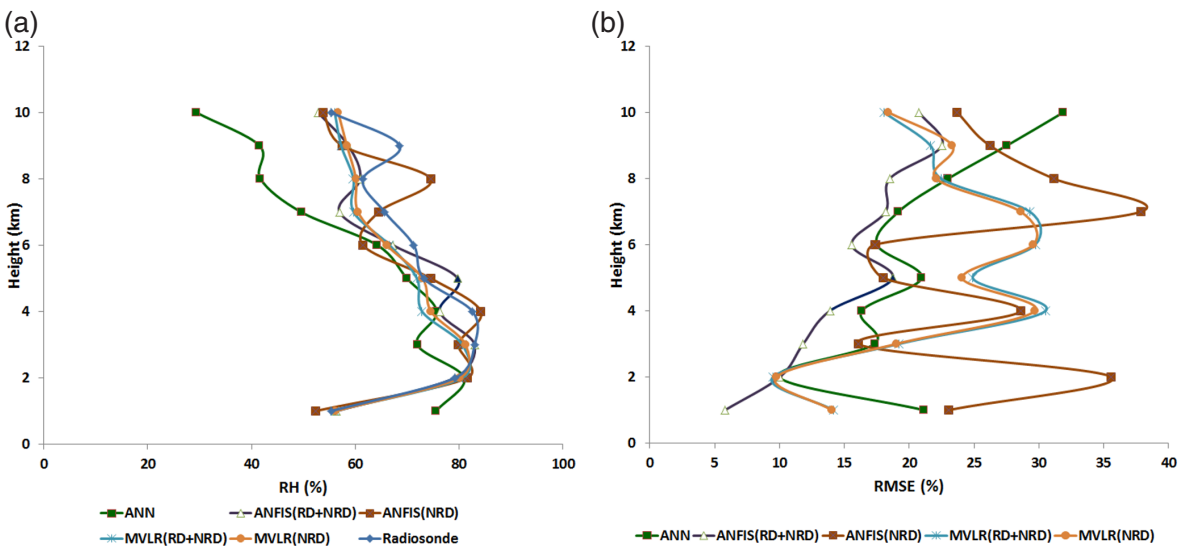

(c)

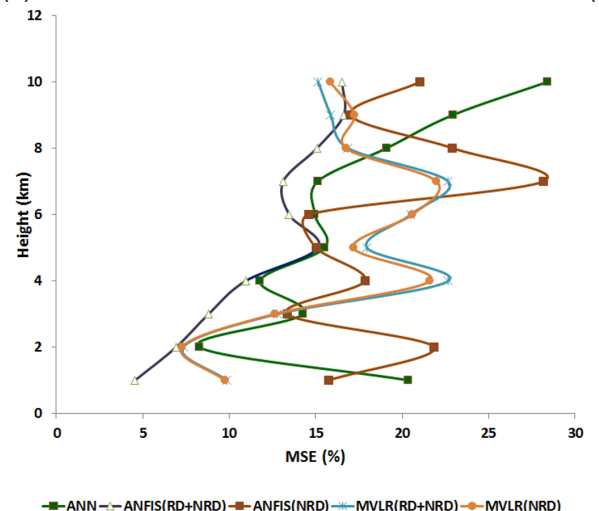

(d)

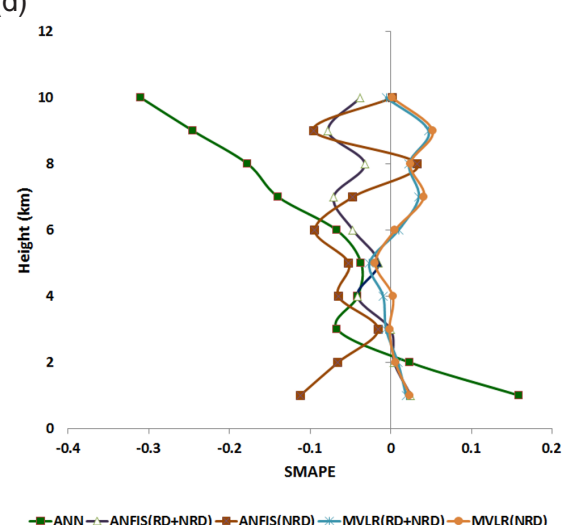

Figure 6. Comparison of vertical profiles of (a) RH observed by radiosonde and temperature profiles retrieved from ANN ANFIS(RD + NRD), ANFIS(NRD), MVLR(RD + NRD) and MVLR(NRD) and (b) RMSE, (c) MAE and (d) SMAPE of retrieved profiles using ANN, ANFIS(RD + NRD), ANFIS(NRD), MVLR(RD + NRD) and MVLR(NRD) with respect to relative humidity profiles observed by radiosonde.

$2{ }^{\circ} \mathrm{C}$ above $4 \mathrm{~km}$. As seen from Fig. $5 \mathrm{~b}$, the ANFIS method is successful in reducing this bias with the average RMSE of 1.08 .

\subsection{Error analysis of retrieved humidity profiles}

Figure 6a-d show the mean profile of retrieved relative humidity using ANFIS, ANN or MVLR models and observed brightness temperatures. The figure shows that the profile retrieved using the ANFIS(RD + NRD) model is qualitatively better compared to that using the ANN model. It is seen from Fig. $6 \mathrm{~b}$ that the RMSE of retrieved relative humidity averaged over the training data set is less than $0.01 \%$ throughout the profile. However, the values of RMSE of the testing data set for ANFIS, vary significantly (5-20\%) with respect to height. At $1 \mathrm{~km}$, the value of RMSE is $4.87 \%$, at $2 \mathrm{~km}$ it is $6.19 \%$ and it gradually increases towards higher heights up to a maximum of $23.89 \%$ at $8 \mathrm{~km}$. It is seen from Fig. 6b that ANFIS(RD+NRD) shows better performance than ANN in retrieving relative humidity. The variation of MAE is more or less consistent with the behaviour of RMSE. The behaviour of SMAPE with height shows that the AN-
FIS model takes into account more variability compared to ANN models but has a more negative bias at higher heights. The study by Venkat Ratnam et al. (2013) also indicated a large wet (dry) bias of $6-8 \mathrm{~g} \mathrm{~kg}^{-1}$ in the specific humidity below (above, except around 5-6 km) 2-3 km between the radiosonde and ANN algorithm.

\section{Conclusions}

In this work, we have presented a formulation of the ANFIS model for the retrieval of atmospheric profile temperature and humidity using brightness temperatures observed at different microwave frequencies mentioned above by MWR. The ANFIS models are trained by considering rainy and nonrainy days together (ANFIS(RD + NRD)) and also only for non-rainy days (ANFIS(NRD)). In this work we found that ANFIS(RD + NRD) is more suitable for retrieving vertical profiles of the atmosphere by observing the power received on the ground due to different emissions at different microwave frequencies. Our results indicated that the performance of the ANFIS(RD + NRD) model is better than the 
ANN back-propagation algorithm in retrieving profiles of both temperature and $\mathrm{RH}$. The retrieved temperature profiles are relatively closer to the observations by radiosonde. However, an improvement is needed in the retrieval of relative humidity to reduce relatively large error at higher heights. For this purpose, a detailed investigation is required to be carried out to understand the behaviour of the brightness temperatures in a cloudy atmosphere and its impact on the weighting functions of MWR and the retrieval of vertical profiles using the ANFIS method. The development of robust algorithms for the retrieval of temperature and relative humidity using the new method ANFIS, especially during complex environmental conditions, will lead to MWR as a novel tool to investigate the physical mechanisms associated with smallscale convections.

Acknowledgements. The authors are thankful to V. Sundareswaran, Regional Director, Anna University, Regional Centre, Tirunelveli, India, for his continuous encouragement and support during this work. Also, thanks are due to A. Kiran Kumar, NARL, Gadanki, India, for his technical support during this work.

Edited by: M. Nicolls

\section{References}

Ajil, K. S., Thapliyal, P. K., Shukla, M. V., Pal, P. K., Joshi, P. C., and Navalgund, R. R.: A New Technique for Temperature and Humidity Profile Retrieval From Infrared-Sounder Observations Using the Adaptive Neuro-Fuzzy Inference System, IEEE T. Geosci. Remot., 48, 1650-1659, April, 2010.

Bacanli, U. G., Firat, M., and Dikbas, F.: Adaptive Neuro-Fuzzy Inference System for drought forecasting, Stoch. Env. Res. Risk A., 23, 1143-1154, 2009.

Basha, G. and Ratnam, M. V.: Identification of atmospheric boundary layer height over a tropical station using high resolution radiosonde reflectivity profiles: Comparison with GPS radio occultation measurements, J. Geophys. Res., 114, D16101, doi:10.1029/2008JD011692, 2009.

Basili, P., Bonafoni, S., Ciotti, P., Marzano, F. S., d'Auria, G., and Pierdicca, N.: Retrieving atmospheric temperature profiles by microwave radiometry using a priori information on atmospheric spatial-temporal evolution, IEEE T. Geosci Remote, 39, 18961905, 2001.

Binco, L., Cimini, D., Marzano, F. S., and Ware, R.: Combining Microwave Radiometer and Wind Profiler Radar Measurements for High-Resolution Atmospheric Humidity Profiling, J. Atmos. Ocean. Tech., 22, 949-965, doi:10.1175/JTECH1771.1, 2005.

Bleisch, R., Kämpfer, N., and Haefele, A.: Retrieval of tropospheric water vapour by using spectra of a $22 \mathrm{GHz}$ radiometer, Atmos. Meas. Tech., 4, 1891-1903, doi:10.5194/amt-4-1891-2011, 2011.

Buyukbingol, E., Sisman, A., Akyildiz, M., Alparslan, F. N., and Adejare, A.: Adaptive neuro-fuzzy inference system (ANFIS): A new approach to predictive modelling in QSAR applications: A study of neuro-fuzzy modelling of PCP-based NMDA receptor antagonists, Bioorgan. Med. Chem., 15, 4265-4282, 2007.

Chan, P. W.: Performance and application of a multi-wavelength, ground-based microwave radiometer in intense convective weather, Meteorol. Z., 18, 253-265, 2009.

Chiu, S. L.: Fuzzy model identification based on cluster estimation, J. Intell. Fuzzy Syst., 2, 267-78, 1994.

Chiu, S. L.: Fuzzy Information Engineering: A Guided Tour of Applications, edited by: Dubois, D., Prade, H., and Yager, R., John Wiley \& Sons, 1997.

Cimini, D., Westwater, E. R., Han, Y., and Keihm, S. J.: Accuracy of ground-based microwave radiometer and balloon-borne measurements during WVIOP2000 field experiment, IEEE T. Geosci. Remote, 41, 2605-2615, 2003.

Cimini, D., Hewison, T. J., Martin, L., Güldner, J., Gaffard, C., and Marzano, F.: Temperature and humidity profile retrievals from ground based microwave radiometers during TUC, Meteorol. Z., 15, 45-56, 2006.

Cimini, D., Westwater, E. R., and Gasiewski, A. J.: Temperature and humidity profiling in the Arctic using milli meter-wave radiometry and 1-DVAR, IEEE T. Geosci. Remote, 48, 1381-1388, doi:10.1109/TGRS.2009.2030500, 2010.

Cimini, D., Campos, E., Ware, R., Albers, S., Giuliani, G., Oreamuno, J., Joe, P., Koch, S., Cober, S., and Westwater, E.: Thermodynamic atmospheric profiling during the 2010 Winter Olympics using ground-based microwave radiometry, IEEE T. Geosci. Remote, 49, 4959-4969, doi:10.1109/TGRS.2011.2154337, 2011.

d'Auria, G., Marzano, F. S., Pierdicca, N., Pinna Nossai, R., Basili, P., and Ciotti, P.: Remotely sensing cloud properties from microwave radiometric observations by using a modelled cloud database, Radio Sci., 33, 369-392, 1998.

Doswell III, C. A.: The Operational Meteorology of Convective Weather. Vol. II: Storm-scale Analysis, NOAA Tech. Memo. ERL ESG-15, available from the author at National Severe Storms Lab., 1313 Halley Circle, Norman, OK, 73069, 1985.

Frate, D. F. and Schiavon, G.: A combined natural orthogonal functions/neural network technique for the radiometric estimation of atmospheric profiles, Radio Sci., 33, 405-410, doi:10.1029/97RS02219, 1998.

Gaffard, C. and Hewison, T.: Radiometrics MP3000 Microwave Radiometer, Trial Report Version 1.0, 2003.

Güldner, J. and Spänkuch, D.: Remote sensing of the thermodynamic state of the atmospheric boundary layer by ground-based microwave radiometry, J. Atmos. Ocean. Tech., 18, 925-933, 2001.

Han, Y. and Westwater, E. R.: Analysis and improvement of tipping calibration for ground-based microwave radiometers, IEEE T. Geosci. Remote, 38, 1260-1275, 2000.

Haobo, T., Mao, J., Chen, H., Chan, P. W., Wu, D., Li, F., and Deng, T.: A Study of a Retrieval Method for Temperature and Humidity Profiles from Microwave Radiometer Observations Based on Principal Component Analysis and Stepwise Regression, J. Atmos. Ocean. Tech., 28, 378-389, doi:10.1175/2010JTECHA1479.1, 2011.

Iassamen, A., Sauvageot, H., Jeannin, N., and Ameur, S.: Distribution of Tropospheric Water Vapour in Clear and Cloudy Conditions from Microwave Radiometric Profiling, J. Appl. Meteorol. Clim., 48, 600-615, 2009. 
Jang, J. R.: ANFIS: Adaptive-Network-Based Fuzzy Inference System, IEEE T. Syst. Man Cybr., 23, 665-685, 1993.

Jang, J.-S. R., Sun, C. T., and Mizutani, E.: Neuro-Fuzzy and Soft Computing. Upper Saddle River, NJ: Prentice-Hall, ser. MATLAB Curriculum Series, 1997.

Jang, J. S. R., Sun, C.-T., and Mizutani, E.: Neuro-Fuzzy and soft computing: A computational approach to learning and machine Intelligence, Pearson Education, 2007.

Knupp, K. R., Coleman, T., Phillips, D., Ware, R., Cimini, D., Vandenberghe, F., Vivekanandan, J., and Westwater, E.: GroundBased Passive Microwave Profiling during Dynamic Weather Conditions, J. Atmos. Ocean. Tech., 26, 1057-1073, 2009.

Lane, T. P. and Moncrieff, M. W.: Characterization of Momentum Transport Associated with Organized Moist Convection and Gravity Waves, J. Atmos. Sci., 67, 3208-3225, doi:10.1175/2010JAS3418.1, 2010.

Lin, L.-C. and Chang, H.-K.: An Adaptive Neuro-Fuzzy Inference System for Sea Level Prediction Considering Tide-Generating Forces and Oceanic Thermal Expansion, Terr. Atmos. Ocean. Sci., 19, 163-172, 2008.

Lo, S.-P.: The Application of an ANFIS and Grey System Method in Turning Tool-Failure Detection, Int. J. Adv. Manuf. Tech., 19, 564-572, 2002.

Löhnert, U., Crewell, S., and Simmer, C.: An integrated approach toward retrieving physically consistent profiles of temperature, humidity, and cloud liquid water, J. Appl. Meteorol., 43, 12951307, 2004.

Löhnert, U. and Maier, O.: Operational profiling of temperature using ground-based microwave radiometry at Payerne: prospects and challenges, Atmos. Meas. Tech., 5, 1121-1134, doi:10.5194/amt-5-1121-2012, 2012.

Madhulatha, A., Rajeevan, M., Ratnam, M. V., Bhate, J., and Naidu, C. V.: Now casting severe convective activity over south-east India using ground-based microwave radiometer observations, J. Geophy. Res., 118, 1-13, 2013.

Matzler, C. and Morland, J.: Refined physical retrieval of integrated water vapour and cloud liquid for microwave radiometer data, IEEE T. Geosci. Remote, 47, 1585-1594, 2009.

Pandey, P. C. and Kakar, R. K.: A Two Step Linear Statistical Technique Using Leaps And Bounds Procedure for Retrieval of Geophysical Parameters from Microwave Radiometric Data, IEEE T. Geosci. Remote, 21, 208-214, 1983.

Priyono, A., Ridwan, M., Allias, A. J., Atiq, R., Rahmat, O. K., Hassan, A., and Ali, M. A. M.: Generation of fuzzy rules with subtractive clustering, J. Teknologi, 43, 143-153, 2005.

Rodgers, C. D.: Inverse methods for atmospheric sounding: Theory and Practice, Series on Atmospheric, Oceanic and Planetary Physics, Vol. 2, Singapole, World Scentic, 2000.

Rose, T., Crewell, S., Löhnert, U., and Simmer, C.: A network suitable microwave radiometer for operational monitoring of the cloudy atmosphere, Atmos. Res., 75, 183-200, 2005.

Shaw, T. A. and Lane, T. P.: Toward an Understanding of Vertical Momentum Transports in Cloud-System-Resolving Model Simulations of Multi scale Tropical Convection, J. Atmos. Sci., 70, 3231-3247, 2013.
Solheim, F., Godwin, J. R., Westwater, E., Han, Y., Keihm, S. J., Marsh, K., and Ware, R.: Radiometric profiling of temperature, water vapour and cloud liquid water using various inversion methods, Radio Sci., 33, 393-404, 1998.

Snider, J. B. and Hazen, D. A.: Surface-based radiometric observations of water vapour and cloud liquid in the temperate zone and in the tropics, Radio Sci., 33, 421-432, 1998.

Stähli, O., Murk, A., Kämpfer, N., Mätzler, C., and Eriksson, P.: Microwave radiometer to retrieve temperature profiles from the surface to the stratopause, Atmos. Meas. Tech., 6, 2477-2494, doi:10.5194/amt-6-2477-2013, 2013.

Sugeno, M. and Kang, G. T.: Structure identification of fuzzy model, Fuzzy Sets Syst., 28, 15-33, 1988.

Takagi, T. and Sugeno, M.: Fuzzy identification of systems and its applications to modeling and control, IEEE Trans. Syst., Man, Cybern., 15, 116-132, 1985.

Tahmasebi, P. and Hezarkhani, A.: Application of Adaptive NeuroFuzzy Inference System for Grade Estimation; Case Study, Sarcheshmeh Porphyry Copper Deposit, Kerman, Iran, Australian Journal of Basic and Applied Sciences, 4, 408-420, 2010.

Takagi, T. and Sugeno, M.: Derivation of fuzzy control rules from human operator's control action, in: Proc. IFAC Symp. Fuzzy inform, Knowledge Representation and Decision Analysis, 5560, 1983.

Venkat Ratnam, M. V., Durga Santhi, Y., Rajeevan, M., and Rao, S. V. B.: Diurnal variability of stability indices observed using radiosonde observations over a tropical station: Comparison with microwave radiometer measurements, Atmos. Res., 124, 21-33, 2013.

Ware, R., Carpenter, R., Güldner, J., Liljegren, J., Nehrkorn, T., Solheim, F., and Vandenberghe, F.: A multichannel radiometric profiler of temperature, humidity, and cloud liquid, Radio Sci., 38, 8079, doi:10.1029/2002RS002856, 2003.

Waters, J. W., Kunzi, K. F., Pettyjohn, R. L., Poon, R. K. L., and Staelin, D. H.: Remote Sensing of Atmospheric Temperature Profiles with the Nimbus 5 Microwave Spectrometer, J. Atmos. Sci., 32, 1953-1969, 10.1175/15200469(1975)032<1953:RSOATP>2.0.CO;2, 1975.

Westwater, E. R.: Ground-based microwave remote sensing of meteorological variables, in: Atmospheric Remote Sensing by Microwave Radiometry, J. Wiley Sons, Inc., edited by: Michael, A. J., Chapter 4, 145-213, 1993.

Westwater, Ed. R., Han, Y., Irisov, V. G., Leuskiy, V. Y., Trokhimovski, Y. G., Fairall, C. W., and Jessup, A. T.: Sea-air and boundary layer temperatures measured by a scanning 5-mm wavelength radiometer: Recent results, Radio Sci., 33, 291-302, 1998.

Xu, G., Ware, R., Zhang, W., Feng, G., Liao, K., and Liu, Y.: Effect of off-zenith observation on reducing the impact of precipitation on ground-based microwave radiometer measurement accuracy in Wuhan, Atmos. Res., 140-141, 85-94, 2014.

Yager, R. and Filev, D.: Generation of Fuzzy Rules by Mountain Clustering, J. Intell. Fuzzy Syst., 2, 209-219, 1994. 